\title{
Rare Books, Manuscripts, and Other Special Collections Materials: Integration or Separation?
}

\author{
William L. Joyce
}

The management of special collections units in contemporary research libraries rarely offers such draconian choices as "integration" or "separation" of those units. Nonetheless, separate patterns of training and experience, variable procedures and conventions in handling materials, and different traditions need to be reviewed before developing administrative structures for special collections units. Factors such as changing patterns of research use, technological innovation, and scarcity of resources, however, appear to indicate that closer administrative ties among special collections units managing disparate materials are indeed at hand. Moreover, the proliferation of types of materials found in special collections, the growing awareness of the concept of "intrinsic value, " and the importance of involving special collections staff in cooperative collection development programs point to the importance of identifying integrated management structures for special collections departments.

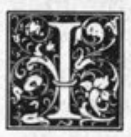

n considering the most appropriate means of managing manuscript holdings, as well as collections of rare books and other special collections materials, the choice is rarely as stark as the alternatives of "integration" or "separation." These terms conjure images rich in historical resonance, but somewhat remote in terms of library economy. Moreover, administrative alternatives are rarely so draconian or presented with such finality. And yet, given the current interest in how to organize and manage special collections within a larger institutional framework, the relation of unpublished to published research materials is of more than passing interest.

Very often, special collections are at least partially underwritten by restricted endowment funds that are no longer sufficient to cover the funds' original purposes. The parent library makes up the deficits, but there is a price for these special collections units to pay: administrative independence and autonomy. (It is worth observing that the phrase "special collections" is an occasion for some mischief, in that the word "special" connotes exclusiveness and distinctiveness. Ironically, this is the very result that administrators often are seeking to avoid.)

For those libraries that contain both published and unpublished research materials, however, closer ties between them appear to be at hand. If indeed it is true that these units are being administratively combined, it would be well to consider first how they might be different by reviewing separate traditions, conventions, and patterns of training and experience. Then, we might discuss some of those factors that seem to indicate that those closer ties are at hand.

Traditions, conventions, and patterns of training and experience among archivists,

William L. Joyce is assistant director for rare books and manuscripts, New York Public Library, New York 10018. This paper was presented at the Rare Books and Manuscripts Section general program meeting at the 1983 ALA Annual Conference in Los Angeles. 
manuscripts curators, and librarians argue for separation and distinct professional identities. This separateness is manifested in education and training, the handling and processing of collections, and research interests.

Rare book librarians derive their professional identity primarily from their masters degrees in library science. Their degrees, together with the identity nurtured by the American Library Association, provide for those who chose rare books as their occupation a clear-cut professional purpose readily understood by most. By contrast, archivists come to their profession from a variety of academic backgrounds, no one of which has been established as the principal avenue to professional success. Archivists do have a professional association, but the current president has selected as his theme "archivists and society" in an effort to explain the work of archivists and their larger purposes to society generally. While there are several archival training programs, and the number is growing, archivists are still being trained as historians, public administrators, and various other academic disciplines, as well as librarians.

Manuscripts curators initially were identified more with librarianship, especially those who entered the field prior to World War II when many manuscript collections were handled primarily like collections of discrete items. More recently, as personal papers increasingly have taken the appearance and nature of institutional records, the archival influence has become more apparent among curators.

Archivists have derived their principles and practices primarily from their European colleagues who, in the nineteenth century, developed the ideas of provenance (material grouped by its office or origin) and respect des fonds (documents organized according to their original filing order). These ideas find primary expression in what the National Archives and Records Service calls "inventories" and the Library of Congress has termed "registers." The primary purpose of these finding aids is to describe documents as a collective entity whose principal meaning and identity derive from the context in which they are found.

From the middle of the nineteenth century, librarians have followed a different approach to organizing and cataloging the materials that they manage. Essentially, this consists of identifying a title, author and other essential characteristics and recording them on cards. In contrast to the work of archivists, librarians work with the individual items, and regard them as cultural artifacts designed to meet a specific cultural purpose. Classification by subject is an important aspect of this activity. Archivists view records as being part of a collective unity in which documents derive meaning from their context and must, therefore, be described collectively. The documents are arranged by their functional origins, not identified by their cultural purpose.

As in most other respects, manuscripts curators hover uneasily between archivists and librarians, borrowing from both, but finding a comfortable place with neither. Initially, manuscripts curators found their primary interest to be in the techniques of librarians, but lately, more have found archival techniques congenial, particularly in light of the changing nature of manuscripts collections which have become more institutional as well as bulky.

The research interests of rare book librarians have been traditionally in bibliography (both descriptive and analytical) and printing history, as well as the study of the book as a cultural artifact (its purpose, audience, and use). The bibliographical approach is primarily borrowed from British librarians, while the view of the book as a cultural artifact is associated principally with the interests of the $A n$ nales school of historians who now dominate French higher education.

By contrast, the research interests of archivists have been focused on preparing administrative histories so that they can understand the contexts in which documents were produced, as well as studying their signs, stamps, endorsements, markings, and other physical attributes. Manuscripts curators have been traditionally and characteristically found in both camps, with interest in both the codex 
form of manuscripts as well as the document considered in and by itself.

Rare book librarians have an advantage over archivists and manuscripts curators inasmuch as their activities are fully integrated into the core functions of libraries.

While there are often problems in dealing with specific items and library procedures may develop some "glitches," rare books can be readily integrated into the parent library's collection development, accessioning, cataloging, conservation, and reference services.

Archival procedures do not find such ready adaptability. Accessioning is done collectively, not by item, while arrangement and description cannot be undertaken by the library technical staff without substantial retraining. While there may be similarities between library and archival materials in terms of conservation and reference services, there has been little record of substantial archival involvement in the formulation of collection development policies in the nation's major research libraries. This is cause both for reflection about the overall relations between librarians and archivists and for concern that more progress has not been made in such a central aspect of library management.

It is true that traditions and conventions have led to a complex set of relations between librarians, archivists, and manuscripts curators. In recent years, however, there also have been a number of factors that have conspired to lead to closer ties among these three groups. These factors are changing patterns of research use, technological change, and what might be directly, if somewhat ambiguously, described as "administrative reality."

A major change in the situation of research libraries has been the changing nature of research conducted in such repositories. Research projects are more interdisciplinary, and scholars are using a wider range of sources, particularly for those topics related to social history. In the past, scholars tended to select categories of sources that corresponded to their topics. Today, there is a wide-ranging interest in topics that combine social, intellectual, and other sources. Genealogical research has boomed in recent years. There also has been a growth in public policy research, while diplomatic, political, and cultural topics seem to have lead scholars into broader, more eclectic fields of research.

The major consequence of this trend towards broader research topics is that scholars need source information that is generic and not limited to particular documentary or artifactual forms. Subject access takes on proportionally greater importance, because scholars are not as likely to know such a broad range of sources. It is, therefore, the responsibility of archivists, librarians, and curators to work together to develop means of getting more information about diverse research sources into the hands of scholars.

A second factor that has narrowed the procedural differences among librarians, manuscripts curators, and archivists is that of technological change. The recent nature of this change has confused the relation between information and the medium in which it is carried. Whether an artifact is a book, microfilm, handwritten or typed document, or newer technological product, it is distinguished from the information it contains. For example, a videodisc can carry both graphic images, text, and music. As one medium develops the capacity to carry different kinds of information, such as the case of machinereadable records, there is increasing emphasis on cataloging the information, not necessarily the medium carrying it.

This trend is likely to be reinforced by the MARC formats in which data elements and their relation to one another are ever more similar. The categories carrying information in the MARC formats are becoming broader and more adaptive. The growing interest in and emphasis on subject access will promote the further breakdown of the differences in formats. A critical factor in the continuing development of similar formats will be the formulation of adaptive and flexible authorities and thesauri that can be applied across formats.

A third factor that is breaking down differences among librarians, archivists, and curators is administrative reality. In an age of scarcity, effective use of existing re- 
sources becomes more important, and duplication of services must be reduced if not eliminated. To accomplish this, staff must be knowledgeable about collections in a variety of formats and media so that patterns of staffing achieve maximum flexibility. Common catalogs and common photoduplication procedures can further reduce duplication of services, while common priorities of preservation can promote closer coordination among special collections units.

Another factor that can lead to integration of special collections units is that there has been a proliferation of materials in special collections beyond those of rare books, pamphlets, newspapers, and manuscripts. Photographs and ephemera are the most prominent of these materials. Both are amenable to the application of archival methods.

The growing use of the concept of "intrinsic value" in determining preservation and conservation priorities is another means by which distinctions between archivists and librarians are reduced. The concept applies equally to published and unpublished materials, and is important in extending the distinction between the medium and the information it carries. Librarians and archivists will work more closely in determining preservation priorities and in applying the concept of "intrinsic value."

A final area about which archivists and rare book librarians should be equally con- cerned is collection development. Neither the RLG conspectus project nor the ARL project appear to incorporate effectively special collections materials, though certainly interinstitutional collection development projects should do so. This is especially true if library administrators are to make progress in integrating research collections units into the ongoing cooperative programs developed by research libraries.

When ascribing the attribute of being "separate" to any unit in any organizational structure, there is an implication of, on the one hand, autonomy and independence, and, on the other, of isolation, lack of participation, and distance. Because they are no longer sufficiently funded, special collections units can no longer operate as duchies, principalities, or other autonomous and independent entities, if indeed they ever could. In order to reduce duplication of services and combat separation and isolation, special collections units have been formed in many libraries containing rare books, manuscripts, and archives.

As special collections librarians, curators, and archivists face changing patterns of research use, dramatic technological changes, and stark administrative realities, it does indeed appear to be time to emphasize cooperative solutions to common problems through integration of services and administrative structures. 